\title{
A escravidão nos impressos do Primeiro Reinado: Chapuis, Plancher e a escravidão
}

Slavery printed in the First Reign: Chapuis, Plancher and slavery

Arthur Ferreira Reis arthurfr23@gmail.com

\begin{abstract}
Resumo: Buscando situar e discutir a questão da escravidão durante o primeiro reinado, analisar-se-á a opinião de dois jornalistas franceses, Pedro Plancher e Chapuis, a partir dos textos publicados em seus jornais, o Spectador Brasileiro e o Verdadeiro Liberal, respectivamente. Mesmo sendo rivais e utilizando argumentos distintos, se perceberá que a defesa do cesse do tráfico negreiro, realizada por ambos, se baseava em informações, argumentos morais, econômicos e religiosos, além de colocar de manifesto questões candentes sobre o futuro dos negros e da agricultura após a medida.
\end{abstract}

Palavras-chave: imprensa, política, Primeiro Reinado

Abstract: Seeking to situate and discuss the issue of slavery during the first reign, will be to analyze the opinion of two French journalists, Pedro Plancher and Chapuis, out of texts published in their newspapers, Spectador Brasileiro and Verdadeiro Liberal, respectively. Even as rivals and using different arguments, the defense of the cessation of the slave trade, held by both, was based on information, moral, economic and religious arguments, besides manifesting questions about the future of black people and agriculture after measurement.

Keywords: press, policy, First Reign

\footnotetext{
* Mestrando pela Universidade Federal do Espírito Santo.
} 
Os anos de 1820 foi um período de intenso debate sobre as diretrizes políticas e sociais do novo arranjo nacional. Por meio de jornais, panfletos e movimentos populares, inúmeros temas foram discutidos e ingressaramna cena pública brasileira. Assunto de primeira importância durante todo o período imperial, a escravidão e o fim do tráfico negreiro alcançaram o primeiro plano nos debates públicos por ocasião da assinatura do tratado de reconhecimento da independência.

Durante o processo de independência, duas elites disputaram a direção dos primeiros anos do novo Império. De um lado, a elite liberal apoiada por atacadistas fluminenses e portugueses recém emigrados (OLIVEIRA, 1999, p.107). Defendiam a soberania popular (OLIVEIRA, 1999, p.130), mesmo que, para eles, a palavra popular fosse reduzida a um público seletivo (OLIVEIRA, 1999, p.147).Usavam para expor suas ideias os jornais Correio do Rio de Janeiro e Revérbero Constitucional Fluminense. O outro grupo que se destacou foi o "Partido Brasileiro", que, desde o inicio, buscou a independência do Brasil para poder guiar os negócios públicos de acordo com seus interesses (OLIVEIRA, 1999, p.127). Faziam suas propostas serem conhecidas através da imprensa, por jornais como O Espelho e o Regulador Brasílico.

O confronto entre as elites serviu para legitimar a imprensa como local de debate. Contando com regras e linguagem própria, buscavam conquistar o príncipe e a opinião pública para seus projetos políticos. Com objetivos políticos, mas também pedagógicos (LUSTOSA, 2000, p.26), introduziram no Brasil uma cultura política liberal fortemente influenciada pelo reformismo português (NEVES, 2003, p.249). Além disso, aguçaram a vontade do povo de participar do momento único, impulsionando manifestações populares, onde demonstravam seus desejos e expressavam suas insatisfações (RIBEIRO, 2001, p.281).

\section{O fim do tráfico negreiro como questão política}

Nesse momento de criação de uma nova nação, a escravidão foi lembrada nos debates. De acordo com Lúcia Maria Bastos Pereira das Neves, a possibilidade do fim da escravidão ou, ao menos, da extinção do tráfico negreiro, já existia desde 1810 (NEVES, 2000). No decorrer dos anos, projetos de suavização dos prejuízos causados pelo provável fim da escravidão ou do tráfico já vinham sendo elaborados por homens como Antonio Pereira Caldas, Hipólito da Costa e o ministro Vilanova Portugal (NEVES, 2000, p.377). Destacou-se também a obra Memória sobre a Necessidade de Abolir a Introdução dos Escravos Africanos no Brasil; sobre o Modo e Condições com que esta Abolição se Deve Fazer; e sobre os Meios de Remediar a Falta de Braços que ela Pode Ocasionar ${ }^{1}$, de João Severiano Maciel da Costa.

Por ocasião da independência o debate se intensificou. A pressão inglesa já se fazia sentir, que, ao se portar como defensora da "humanidade", queria fazer valer os acordos feitos com outros países no Congresso de Viena. O contexto ideal para conseguir que o Brasil também se comprometesse com o fim do tráfico de escravos veio com a necessidade do reconhecimento da independência.

\footnotetext{
${ }^{1}$ COSTA, João Severiano Maciel da. Memória sobre a Necessidade de Abolir a Introdução dos Escravos Africanos no Brasil; sobre o Modo e Condições com que esta Abolição se Deve Fazer; e sobre os Meios de Remediar a Falta de Braços que ela Pode Ocasionar. Coimbra:Imprensa da Universidade Coimbra, 1821.
} 
$\mathrm{O}$ assunto encontrou repercussão nos jornais. De acordo com Alain El Youssef, "a maioria dos artigos que trataram do tema foram favoráveis ao fim do tráfico e da própria escravidão." (YOUSSEF, 2011, p.79). Nesse contexto de debate sobre o tratado com a Inglaterra, segundo Youssef, defender o fim do tráfico era se por ao lado do Imperador, e, da mesma maneira, ir contra o tratado era fazer oposição (YOUSSEF, 2011, p.87). É nesse momento de politização do fim do tráfico negreiro que dois jornalistas franceses encontram-se inseridos. Redator do jornal $O$ Verdadeiro Liberal, Mr. de Chapuis fazia velada oposição aos membros do governo. No lado oposto, dono de uma tipografia e fundador do jornal OSpectador Brasileiro, Pierre Plancher usou seu periódico para defender o governo imperial e, principalmente, o Imperador. Entretanto, mesmo de lados opostos na cena política, militaram em defesa do fim do tráfico negreiro.

A posição de ambos os autores podem nos ajudar a elucidar a posição da elite intelectual existente na Corte.Essa elite intelectual, composta por jornalistas e livreiros, normalmente éconsiderada um meio da elite política ou econômica promover seus projetos e buscar apoio na opinião pública. Entretanto, pode-se perceber claramente que iam muito além das propostas feitas no âmbito político, propostas essas que não tinham, muitas vezes, o compromisso de ser conciliadas com os interesses econômicos, as possibilidades políticas e os anseios sociais.

\section{A Hierarquização da Sociedade}

Na busca de compreender o arranjo político que se efetuou por ocasião da independência, o estudo de Ilmar Mattos ganhou destaque. Os comentários de Mattos sobre o período de independência apontam, de maneira brilhante e figurativa, para a existência da "moeda colonial", onde,do lado da "cara", está a face metropolitana, do lado da "coroa", a face colonial (MATTOS, 1990, p.20). Segundo o autor, a "moeda colonial" fazia com que os "colonos"(proprietários brasileiros) fossem dependentes dos “colonizadores”(elite metropolitana). Com a intensificação da fiscalização e dos impostos (em decorrência da crise iniciada com a transferência da Corte) por parte do colonizador, a metrópole acabou invadindo e incomodando o espaço dos colonos. Gerouse a necessidade,por parte dos colonos de, caso quisessem continuar sendo proprietários, romper com a metrópole (MATTOS, 1990, p.32).

A nova configuração política gerada ainda pela vinda da Corte deu a oportunidade aos proprietários do Centro-Sul, conhecidos como "homens de uma espécie nova", de assumir lugar de destaque na vida política e social do Império Luso-Brasileiro. Através de uma aliança com políticos, após a independência,começaram a fazer valer seus interesses latifundiários(MATTOS, 1990, p.49). Esse aliançacristalizou-se através de negócios, uniões matrimoniais e nobilitação dos que circulavam na Corte. Atrairam também para sua órbita os bacharéis em direito formados em Coimbra ${ }^{2}$, que se transformaram em representantes dos latifundiários (MATTOS, 1990, p.66). Com isso, segundo Ilmar

\footnotetext{
${ }^{2}$ Um estudo mais elucidativo e completo sobre esses magistrados formados em Coimbra foi feito por José Murilo de Carvalho. De igual importância e qualidade, a pesquisa de Murilo também se destaca na busca de compreender a formação do Império. Cf:CARVALHO, José Murilo de. A Construção da Ordem: a elite política imperial / O Teatro das Sombras. Rio de Janeiro: Civilização Brasileira, 2003.
} 
Mattos, a cidade do "Rio de Janeiro foi-se constituindo o feixe de forças políticas que concretizaria o rompimento com as Cortes portuguesas em 1822."(MATTOS, 1990, p.54).

A aliança entre políticos e a classe senhorial fez com que, cada vez mais, conseguissem fazer os interesses latifundiários sobressaírem na nação. O ápice da aliança aconteceu sob a direção Saquarema. Desta maneira, "enobrecidas e condecoradas pelo Estado imperial, essas famílias ligaram suas vidas a ele, ao qual não raroconcebiam como instrumento de seus interesses corporativos"(MATTOS, 1990, p.67). Baseavam sua união em princípios como ordem e civilização (MATTOS, 1990, p. 3), constituindo uma classe, onde

A vivência de experiências comuns, experiências essas que lhes possibilitavam sentir e identificar seus interesses como algo que lhes era comum, e desta forma contrapor-se a outros grupos de homens cujos interesses eram diferentes e mesmo antagônicos aos seus constituia-se, sem dúvida, na condição para uma transformação. Intimamente ligados ao aparelho de Estado, expandiam seus interesses, procuravam exercitar uma direção e impunham uma dominação.(MATTOS, 1990, p.57)

A divisão social também era importante. Para manter a ordem e continuar a desenvolver a civilização, apostaram na hierarquização da sociedade. Aos proprietários de outrem e de si mesmos, coube a direção da sociedade, responsáveis pelo mundo do governo(MATTOS, 1990, p.117). Aos escravos, protagonistas de rebeliões e insurreições, coube o mundo do trabalho(MATTOS, 1990, p.119). Aos livres pobres, desempregados e desorientados dentro da sociedade, o mundo da desordem(MATTOS, 1990, p.121). Responsável pelomundo do governo, a boa sociedade devia governar a casa e o Estado, coibindo exageros dos cidadãos ativos e, principalmente, dos escravos e livres pobres (MATTOS, 1990, p.120). Formavam uma sociedade dividida nos mundos do

$$
\begin{aligned}
& \text { Governo, trabalho e desordem - os } \\
& \text { mundos constitutivos do império do } \\
& \text { Brasil, mundos que se tangenciavam, por } \\
& \text { vezes se interpenetravam, mas que não } \\
& \text { deveriam confundir-se, por meio da } \\
& \text { diluição de suas fronteiras, mesmo que } \\
& \text { os componentes da boa sociedade, } \\
& \text { fossem obrigados a recorrer à repressão } \\
& \text { mais sangrenta a fim de evitar que tal } \\
& \text { acontecesse. (MATTOS, 1990, p. 123) }
\end{aligned}
$$

O resultado dessa união foi lucrativo para a classe senhorial. Segundo Ilmar Mattos, na década de 1850 o Brasil alcançou o monopólio virtual do café, chegando a $60 \%$ da produção mundial (MATTOS, 1990, p.63). Entretanto, a medida que a economia cafeeira crescia, também se tornava ainda mais necessária a proteção de seus representantes. A expansão cafeeira fez com que as fronteiras sociais e territoriais das fazendas se alargassem, aumentando o conflito com posseiros e escravos (MATTOS, 1990, p.70). Dessa maneira,

$$
\begin{aligned}
& \text { Fundar o império do Brasil, consolidar a } \\
& \text { instituição monárquica e conservar os } \\
& \text { mundos distintos que compunham a } \\
& \text { sociedade faziam parte do longo e } \\
& \text { tortuoso processo no qual os setores } \\
& \text { dominantes e detentores de monopólios } \\
& \text { construíram a sua identidade enquanto } \\
& \text { uma classe social (MATTOS, 1990, p. } \\
& \text { 126). }
\end{aligned}
$$

Como estavam, ou se propunham a estar, diretamente ligados ao Estado, faziam seus interesses prevalecer, construindo o arcabouço político e social do Estado segundo o que lhes convinham(MATTOS, 1990, p.69)Guiando o estado de acordo com seus interesses, fica explícito que os proprietários donos de fazendas escravistas colocaram a manutenção da ordem 
escravista e latifundiária no topo das prioridades do Estado, fazendo "com que a Coroa assuma, deste modo, o papel de um Partido"(MATTOS, 1990, p. 92).

\section{Dois Intelectuais no Debate}

Como já apontado, o fim do tráfico negreiro foi amplamente discutido no Primeiro Reinado. Para Youssef, o grande problema foi D. Pedro I não consultar previamente a Câmara dos Deputados sobre um assunto de tamanha importância (YOUSSEF, 2011, p.90). Além disso, o fim do tráfico negreiro era visto como um caminho sem volta rumo ao fim da escravidão, o que prejudicaria, de maneira incalculável, os planos dos grandes fazendeiros. Sendo assim, o fim do tráfico pode ser considerado um dos principais motivos para a deflagração da oposição ao executivo no Primeiro Reinado (PARRON, 2009, p.63). Não sem motivo, é em 1826 que os representantes da elite econômica do Centro-Sul começaram a fazer oposição organizada ao governo imperial (LENHARO, 1979, p.22). Segundo Youssef, as críticas à D. Pedro I sobre o tratado continuaram até 1828 , e após isso, os opositores passaram a acusar o governo imperial de ser incapaz de preparar o país para as consequências que o fim do tráfico traria (YOUSSEF, 2011, p. 95).

Com excessão da recente tese de mestrado de Youssef, poucos estudos se concentram na atuação da imprensa dos anos de 1820 sobre a escravidão. Levando em conta as conclusões de Ilmar Mattos, fica claro que a elite intelectual fluminense tinha um projeto social distinto das elites política e econômica, defensora da escravidão e do tráfico.Sendo assim, mesmo sob protesto dos jornalistas e de políticos ligados a elite intelectual $^{3}$, o governo seguiu defendendo a ordem escravista, de forma explícita ou não, confirmando o que Emilia Viotti chamou de "o limite do liberalismo no Brasil" (COSTA, 1971, p.92). Esse caso de discordância entre a elite intelectual e as elites política e econômica fica ainda mais claro quando observamos dois autores com posições políticas distintas, mas que se portaram contra o tráfico negreiro. Percorreremos então as páginas dos jornais $O$ Verdadeiro Liberal e $O$ Spectador Brasileiro para podermos perceber quais as opiniões desses homens.

Das poucas informações que temos do francês Mr. de Chapuis, sabemos que teve uma breve passagem por Espanha e Portugal, sendo expulso de ambos os países por suas opiniões políticas radicais (O SPECTADOR BRASILEIRO, 15 mar. 2014).

A primeira notícia que temos de Chapuis no Brasil remete a um poema publicado em 15 de Novembro de 1825 no Diário do Rio de Janeiro, onde fazia referência ao nascimento de D. Pedro I (DIÁRIO DO RIO DE JANEIRO, 15 nov. 1825).

Seu jornal $O$ Verdadeiro Liberal teve vida curta, contabilizando apenas 16 exemplares, que vão de 02 de março de 1826 até 06 de abril do mesmo ano. Como de praxe em sua vida, foi exilado do Brasil em 17 de abril.

Nosso segundo jornalista, o também francês Pierre Plancher é mais famoso. Livreiro de sucesso, dono da Typographia de Plancher, criou três jornais: $O$ Spectador Brasileiro, L'Indépendant - Feuille de Commerce, Politique et Littéraire, e o mais famoso deles, o Jornal do Commercio. Chegou ao Brasil em 27 de março de 1824 (PACHECO, 1917), e, desde sua chegada, utilizou seus jornais para fazer defesa do

\footnotetext{
${ }^{3}$ Podemos observar esse caso em José da Silva Lisboa (Visconde de Cairu) e José Bonifácio. Cf. ROCHA, AntonioPenalves. Idéias antiescravistas da ilustração na sociedade escravista brasileira. In: SIMPÓSIO NACIONAL DE HISTÓRIA, 23, 2005, Londrina. Anais do XXIII Simpósio Nacional de História - História: guerra e paz. Londrina: ANPUH, 2005.
} 
governo imperial. Sua estadia foi longa, e apenas em 1834 voltou para a França, provavelmente rico após ter vendido sua tipografia e sua livraria (PACHECO, 1917, p. 112).

Suas posições políticas não cabem no limite desse trabalho, mas faremos um breve resumo de suas opiniões. Para Chapuis, a constituição e o legislativo eram sobranceiros ao Executivo. A constituição era a "única taboa em que se podem salvar os Brasileiros dos males das revoluções, e das guerras, tanto civis como estranhas." (O VERDADEIRO LIBERAL, 16 mar. 1826).

Além disso, deixava bem claro suas posições a respeito da soberania popular. Segundo ele, havia sido "a Nação quem proclamou a sua Independência", sendo"o Príncipe forçado pelas circunstâncias a unir os seus interesses aos da Nação..." (O VERDADEIRO LIBERAL, 16 mar. 1826).

Já Plancher, defensor da soberania monárquica, defendia o Imperador como "o mais firme Garante de Sua liberdade." (O SPECTADOR NACIONAL, 03 abr. 1826). Essa soberania se reflete também em relação à independência. Diferente de seu compatriota, a independência, em sua opinião, havia sido "proclamada pelo nosso Immortal Defensor", cabendo aos brasileiros, "animados com a Augusta Presença de S.M. o Imperador, applaudimos, e abraçamos a declaração da Independencia", que "nos remio da intentada escravidão das Cortes". (O SPECTADOR NACIONAL, 13 mar. 1826)

Essa rápida explicação serve para mostrarmos como ambos os jornalistas posicionavam-se comideias distintas no jogo político fluminense. Chapuis, defensor da soberania popular, afirmava que a responsabilidade pela formação do novo pacto entre povo e Imperador havia sido da Nação. Diante dessa vontade unânime de todos os habitantes do país, coube ao Imperador apenas aceitar o destino da nação e unir-se a ele. Já para Plancher, foi D. Pedro I o proclamador da independência, pois havia percebido que havia chegado a hora de o Brasil se emancipar.

Chapuis considerava o tráfico de escravos "um commercio abominável, que offende tanto a Religião, como a Moral, e que deve ser prohibido." (O VERDADEIRO LIBERAL, 18 mar. 1826). Para o redator, a gradual proibição do tráfico em nada atrapalharia o desenvolvimento nacional, mas reconhecia que

provar ao agricultor, que a importação dos escravos ao Brasil não he de utilidade alguma, e que elle mesmo ganhará com esta prohibição, não he tarefa de um dia: será necessário tempo para lhe persuadir.

A solução para o fim do tráfico seria tratar

bem os escravos, que dando-lhes melhores alimentos, que cuidando nas suas enfermidades e fazendo-os adquirir amor e interesse á casa, augmentará, triplicará a sua cultura, e que sem comprar um só escravo, terá sempre tantos braços quantos lhe forem necessários.

Devia-se mostrar aos agricultores, no decorrer dos quatro anos, que se antes

vós gastais dous contos de réis cada anno em compra de escravos; mui bem, tratando melhor, os que já possuia, tendo cuidado das pretas, educando com mais humanidade os creolos, não necessitareis comprar mais alguns, ganharei todos os annos esses dous contos,e o vosso trabalho augmentar-se-ha... (O VERDADEIRO LIBERAL, 18 mar. 1826)

Com isso, apoiou o governo na decisão de não abolir de vez o tráfico negreiro, pois "uma medida de tal importância não deve ser precipitada, e que o Governo Brasileiro, quando tratou de conceder os quatro annos conciliou sabiamente todos os interesses", 
pois, caso fosse abolido imediatamente, seria "um golpe fatal, não só na agricultura, como na industria em geral", o que iria "paralisar todos os meios de produção"e "atacar na fonte a prosperidade do Estado" (O VERDADEIRO LIBERAL, 18 mar. 1826). Oposição no que diz respeito a propostas políticas, defendeu o governo imperial na questão do fim do tráfico.

Já Plancher foi mais minucioso quando defendeu o fim do tráfico negreiro. Suas opiniões, foram publicadas transcrevendo a obra Cours D'écon. polit., do economista, estatístico e historiador russo Heinrich Friedrich Von Storch. Para Plancher, faltavam "luzes" aos brasileiros para poderem compreender que o ministério estava certo ao se comprometer com o fim do tráfico negreiro. Buscou, além de opinar politicamente, trabalhar de maneira pedagógica para ensinar aos brasileiros os reais benefícios da decisão do ministério. Nesse sentido, uma das primeiras desvantagens causadas pela escravidão era a baixa população do país. O texto transcrito, traduzido e publicado no $O$ Spectador Nacional afirmava que

a escravidão, da mesma sorte que toda a administração oppressiva, he hum dos mayores obstáculos à população. Onde os escravos se compõem de estrangeiros, que se introduzem no pays, os Senhores achão em geral que he mais proficuo compra-los já feitos, do que cria-los em casa; assim para manterem o numero necessário, convem recruta-los todos os annos. Onde elles se compõem de nacionaes, á sua multiplicação nunca iguala a dos homens livres. (18 jan. 1826).

De acordo com Plancher, graças à busca incessante por escravos, causadora de guerras, os Estados escravistas da antiguidade tinham uma baixa população. Afirmava também que a difícil travessia do Atlântico causava uma grande mortalidade dos escravos, o que acabava diminuindo sua expectativa de vida e ainda mais a população (O SPECTADOR NACIONAL, 03 fev. 1826).

Ainda por meio da mesma transcrição, o periódico de Plancher destacava que o segundo problema causado pela escravidão era a degradação moral, tanto dos escravos, quanto dos senhores. Segundo ele,
Qualquer que tenha observado os effeitos da escravidão; qualquer que tenha meditado sobre este objecto, não pode dissimular-se que esta desgraçada relação corrompe igualmente a alma do escravo, e do Senhor. Notamos já quanto a falta de estabelidade, a que he exposto o escravo, tende a faze-lo preguiçoso, descuidado, ladrão, dissipador e bêbado: o seu estado the faz contractar de mais outros hábitos não menos funestos aos bons costumes e á prosperidade individual e social(...) mas debaixo deste exterior enganoso, elle occulta hum coração ulcerado pela injustiça da sua situação (O SPECTADOR NACIO- NAL, 03 fev. 1826).

Dessa maneira, por mais que o escravo tivesse um bom coração, a sua condição injusta e degradante acabaria destruindo sua moral e o transformando em um ser preguiçoso e ladrão. A degradação moral do escravo acabava se refletindo no seu senhor, que "rodeado de escravos desde a sua infância, como resistirá o coração do senhor moço ao veneno da lisonja e do deleite, aos agrados vergonhosos e servis que os seus escravos lhe prodigalisão?" (O SPECTADOR NACIONAL, 03 fev. 1826).

Outro problema da escravidão, segundo Plancher, era a desordem social. Descontentes com sua situação, os escravos tendiam a revoltar-se, causando "rebelliões tanto parciaes como geraes" (O SPECTADOR NACIONAL, 08 fev. 1826). A alternativa à escravidão proposta por Plancher era, inicialmente, a reprodução interna de escravos e a posterior utilização 
de trabalhadores europeus, que seriam trazidos por intermédio do governo. Em sua visão,

Virá tempo em que a experiencia mostre, assim como em outros payzes, que o serviço de homens livres assalariados, he muito mais perfeito e vantajoso, do que o de miseráveis escravos, que nenhum interesse tomão em servir, e que se o fazem, he só contragi-los pelo açoute de quem os trata como authomatos, e ás vezes ainda peyor do que as suas bestas. (O SPECTADOR NACIONAL, 08 fev. 1826)

A substituição da mão de obra escrava pela livre e assalariada causaria muitas melhorias, como o crescimento da população, que "he para admirar que os fazendeiros argumentem em favor com a falta d'ella, sem attenderem que a escravatura he hum dos seus mayores obstáculos". Porém, também se veria que “os fundos empregados na compra de escravos podem ser applicados em milhares de especulações lucrativas, de que resultem os salário dos trabalhadores livres, sem o perigo dese perderem pela morte do escravo." (O SPECTADOR NACIONAL, 08 fev. 1826)

Geraria também um maior emprego dos livres pobres nas oficinas, que "fogem d'ellas por se não sugeitarem ás direcções e castigos de hum escravo contra-mestre, ou primeiro director dos trabalhos de seus parceiros." Além disso, a moral

não será tão corrompida, nem a corrupção tão publica, e tão escandalosa, porque não haverão mais negros e negras atulhando as nossas ruas e as nossas casa, dando máo exemplo com palavras e acções á incauta mocidade, invenenando os bons costumes até no interior das familias. (O SPECTADOR NACIONAL, 08 fev. 1826).

Como percebido, ambos os autores se utilizam do tratado de reconhecimento da Independência para defenderem o fim gradual do tráfico negreiro. A intensidade da defesa do fim do tráfico é justificada pelas posições políticas de cada autor. Plancher, eterno defensor do governo imperial, defendeu o fim do tráfico de maneira veemente se não por opiniões pessoais, sim por posição política. Já Chapuis, considerado pelos contemporâneos, um jornalista de oposição (O VERDADEIRO LIBERAL, 11 mar. 1826), também foi contra o tráfico negreiro, mesmo que de maneira velada. Se, como afirmou Youssef, a posição dos jornalistas sobre o fim do tráfico negreiro era esclarecedora sobre sua opinião política (YOUSSEF, 2011, p. 87), o caso de Plancher e Chapuis fica como um ponto de interrogação. Vale destacar também a atuação de João Maria da Costa através do periódico Atalaia da Liberdade, que, na mesma situação política de Chapuis, foi árduo defensor do fim do tráfico negreiro e, até mesmo, da escravidão.

A análise dos autores reforça a tese de Penalves de que, no Brasil, o argumento econômico foi o mais utilizado para fazer oposição à escravidão ou ao tráfico negreiro (ROCHA, 2000, p. 44). Segundo Penalves, esses homens "estavam de fato convencidos de que a escravidão impedia a prosperidade" (2000, p. 53). Além disso, e, ao menos Plancher, também entendiam que o fim da escravidão seria o "fim de um percurso marcado pela sucessão das seguintes etapas: fim do tráfico negreiro, abrandamento da escravidão sob o controle do Estado e início da abolição gradual." (2000, p. 57).

\section{Conclusão}

Por meio dessa pesquisa, buscamos problematizar a opinião de Plancher e Chapuis a respeito do fim do tráfico negreiro. Como dito acima, grande parte da historiografia estuda os jornais e a elite intelectual em geral como integrante de determinado grupo político. Principalmente nos primeiros anos do Primeiro Reinado, quando ainda não existiam grupos políticos tão bem 
organizados como os grupos moderador, exaltado $e$ caramuru, é difícil perceber uma aliança tão clara entre políticos e intelectuais. Muitas vezes os pesquisadores não levam em consideração as diferentes propostas que integravam a elite intelectual que, às vezes, não estavam em acordo com a elite política ou econômica. Como exemplo disso, Plancher e Chapuis, mesmo tendo opiniões políticas distintas, defendiam um ponto de vista parecido sobre o fim do tráfico negreiro, um assunto tão disputado politicamente no período estudado. Percebe-se a carência de um estudo mais atento às propostas da elite intelectual, ao menos do Primeiro Reinado, que mesmo dispersas, não podem ser desconsideradas.
Além disso, o estudo desses homens e suas opiniões sobre o tráfico de escravos devem ser comparados com as conclusões de Ilmar Mattos. Se para o autor a sociedade do Segundo Reinado era hierarquizada e defendia a instituição da escravidão e do tráfico através da direção Saquarema, o Primeiro Reinado não foi assim. A existência de uma elite política e econômica não excluiu a independência de propostas da elite intelectual. Essas elites, mesmo que por vezes se interceptassem, tinham propostas distintas, e tiveram que se sobrepor ou entrar em consenso para compor o novo arranjo nacional.

\section{Referências Bibliográficas}

COSTA, Emília Viotti da. Introdução ao estudo da emancipação política do Brasil. In: MOTA, Carlos Guilherme (org.). Brasil em Perspectiva. $3^{\circ}$ ed. São Paulo: Difel, 1971, p.137-174.

LENHARO, Alcir. As tropas da moderação: o abastecimento da Corte na formação política do Brasil - 1808 1842. São Paulo: Símbolo, 1979

LUSTOSA, Isabel. Insultos impressos: a guerra dos jornalistas na Independência (1821-1823). São Paulo: Companhia das Letras, 2000.

MATTOS, Ilmar R. de. O Tempo Saquarema. A Formação do Estado Imperial. $2^{\circ}$ ed São Paulo: Hucitec, 1990.

MOREL, Marco. As transformações dos espaços públicos: imprensa, atores políticos e sociabilidades na Cidade Imperial (1820-1840). São Paulo: HUCITEC, 2005,

NEVES, Lúcia Maria Bastos Pereira das. Corcundas e constitucionais: a cultura política da Independência (18201822). Rio de Janeiro: Revan / FAPERJ, 2003

NEVES, Lúcia Maria Bastos Pereira das. Por Detrás Dos Panos: atitudes antiescravistas e a independência. In: SILVA, Maria Beatriz Nizza da (org.). Brasil: Colonização e escravidão. Rio de Janeiro: Nova Fronteira, 2000, p.373-395.

OLIVEIRA, Cecília Helena Lorenzoni de Salles. A astúcia Liberal: Relações de mercado e projetos políticos no Rio de Janeiro (1820-1824). Bragança Paulista: EDUSF e ÍNCONE, 1999.

PACHECO, Felix. Hum Francez Brasileiro: Pedro Plancher. Rio de Janeiro: Typ. do "Jornal do Commercio", de Rodrigues \& C., 1917.

PARRON, Tâmis Peixoto. A política da escravidão no Império do Brasil, 1826-1865. 2009. 289 f. Dissertação (Mestrado em História) - Universidade de São Paulo, São Paulo, 2009.

RIBEIRO, Gladys Sabina. A Liberdade em Construção: Identidade Nacional e conflitos antilusitanos no Primeiro Reinado. 1997. 550 f. Tese (Doutorado em História) - Universidade de Campinas, Campinas, 2001, 
ROCHA, Antonio Penalves. Idéias antiescravistas da Ilustração na sociedade escravista brasileira. Rev. bras. Hist. [online]. 2000, vol.20, n.39, pp. 37-68. Disponível em: <http://www.scielo.br/pdf/rbh/v20n39/2981.pdf>. Acesso em: 19/02/2015.

YOUSSEF, Alain El. Imprensa e escravidão: política e tráfico negreiro no Império do Brasil (Rio de Janeiro, 1822 -1850). 2011. 300 f. Dissertação (Mestrado em História) - Universidade de São Paulo, São Paulo, 2011.

\section{Periódicos}

Diário do Rio de Janeiro, n. 318, 15 nov. 1825.

O Spectador Nacional, n. 225, 18 jan. 1826.

O Spectador Nacional, n. 231, 03 fev. 1826.

O Spectador Nacional, n. 233, 08 fev. 1826.

O Spectador Nacional, n. 247, 13 mar. 1826.

O Spectador Brasileiro, n. 248, 15 mar. 2014.

O Spectador Nacional, n. 254, 03 abr. 1826.

O Verdadeiro Liberal, n. 5, 11 mar. 1826.

O Verdadeiro Liberal, n. 7, 16 mar. 1826.

O Verdadeiro Liberal, n. 8, 18 mar. 1826.

Submissão: $13 / 10 / 2015$ Aceite: 01/06/2016 